TABLE IV-One way analysis of variance of between group differences for mean improvement in work done for shoulder abduction and flexion over study period for three injection regimens (50 shoulders)

\begin{tabular}{|c|c|c|c|c|c|}
\hline \multirow[b]{2}{*}{ Movement } & \multicolumn{3}{|c|}{$\begin{array}{l}\text { Improvement in work done over } 16 \text { weeks } \\
(\mathrm{J} / \text { week }(95 \% \text { confidence interval }))\end{array}$} & \multirow[b]{2}{*}{$F$ value } & \multirow[b]{2}{*}{ p Value } \\
\hline & Distension only & Steroid only & Steroid and distension & & \\
\hline Abduction & $0.4(0.1$ to 0.7$)$ & $0.8(0.4$ to 1.2$)$ & $0.9(0.6$ to 1.7$)$ & 1.92 & $>0.05$ \\
\hline Flexion & $0.7(0.3$ to 1.1$)$ & $1.0(0.4$ to 1.6$)$ & $0.9(0.5$ to 1.4$)$ & 0.56 & $>0.05$ \\
\hline
\end{tabular}

TABLE $\mathrm{V}-$ One way analysis of variance of between group differences for mean improvement in torque produced for shoulder abduction and flexion over study period for three injection regimens ( 50 shoulders)

\begin{tabular}{|c|c|c|c|c|c|}
\hline \multirow[b]{2}{*}{ Movement } & \multicolumn{3}{|c|}{$\begin{array}{l}\text { Improvement in torque over } 16 \text { weeks } \\
(\mathrm{N} . \mathrm{m} / \text { week }(95 \% \text { confidence interval }))\end{array}$} & \multirow[b]{2}{*}{$F$ value } & \multirow[b]{2}{*}{ p Value } \\
\hline & Distension only & Steroid only & Steroid and distension & & \\
\hline Abduction & $0.3(0.0$ to 0.6$)$ & $0.5(0.2$ to 0.9$)$ & $0.6(0.1$ to 1.2$)$ & $1 \cdot 29$ & $>0.05$ \\
\hline Flexion & $0.6(0.3$ to 0.9$)$ & $0 \cdot 7(0 \cdot 3$ to $1 \cdot 1)$ & $0.7(0.5$ to 0.8$)$ & 0.01 & $>0.05$ \\
\hline
\end{tabular}
anaesthetic injection has been recommended for capsulitis. ${ }^{26}{ }^{27}$ This requires a more costly inpatient stay with general anaesthesia and immediate postoperative physiotherapy. There are also the risks of fracture of the humeral neck and rupture of the rotator cuff when the procedure is performed by an inexperienced surgeon. Our study indicates a positive role for intraarticular steroid injections in the early outpatient management of capsulitis of the shoulder.

We thank Lederle Laboratories (Cyanamid of Great Britain Ltd) and Astra Pharmaceuticals for funding part of this study. We also thank Mrs M Tew and Dr J Pearson for statistical advice when preparing this paper and the Audiovisual department, University Hospital, Queen's Medical Centre, Nottingham, for help with the illustrations.

I Codman EA. The shoulder. Boston: Thomas Todd, 1934

2 Duplay ES. De la périarthrite scapulo-humérale et des raideurs de l'epaule qui en sont la consequences. Archives Générales de Médecine 1872;20:513-42

Grey RG. The natural history of "idiopathic" frozen shoulder. I Bone foint Surg 1978;60A:56

4 Rowe CR, Leffert RD. Idiopathic chronic adhesive capsulitis ("frozen houlder" In: Rowe CR, ed The shoulder. New York: Churchill Living. tone, 1988:155-63.

5 Simmonds FA. Shoulder pain with particular reference to the "frozen shoulder." F Bone foint Surg 1949;31B:426-32.

6 Reeves B. The natural history of the frozen shoulder syndrome. Scand $f$ Rheumatol 1975; 4: 193-6.

7 Binder Al, Bulgen DY, Hazleman BL, Roberts S. Frozen shoulder: a longterm prospective study. Ann Rheum Dis 1984;43:361-4.

8 Bassey EJ, Morgan K, Dallosso HM, Ebrahim SBJ. Flexibility of the shoulder joint measured as range of abduction in a large representative sample of men and women over 65 years of age. Eur 7 Appl Physiol 1989;58:353-60.

9 Germain NW, Blair SN. Variability of shoulder flexion with age, activity and sex. Am Correct Ther f 1983:37 (6):156-60.

10 Lee PN, Lee M, Haq AMMM, Longton EB, Wright V. Periarthritis of the shoulder; trial of treatments investigated by multivariate analysis. $A n n$ Rheum Dis 1974:33:116-9.

11 Murnaghan GF, McIntosh D. Hydrocortisone in painful shoulder - a controlled trial. Lancet 1955;ii:798-800.

12 Bulgen DY, Binder AI, Hazleman BL, Dutton J, Roberts S. Frozen shoulder: prospective clinical study with an evaluation of three treatment regimens. Ann Rheum Dis 1984;43:353-60

13 Dacre JE, Beeney N, Scott DL. Injections and physiotherapy for the painful stiff shoulder. Ann Rheum Dis 1989;48:322-5.

14 Andrén L, Lundberg BJ. Treatment of rigid shoulder by joint distension during arthrography. Acta Orthop Scand 1965;36:45-53.

15 Older MWJ. Distension arthrography of the shoulder joint. In: Bayley I, Kessel L, eds. Shoulder surgerv. Berlin: Springer-Verlag, 1982:123-7.

16 Fareed DO, Gallivan WR. Office management of frozen shoulder syndrome. Clin Orthop 1989;242:177-83.

17 Wallace WA, Echeverri A. Intra-articular distension with local anaesthetic, steroid and air in the treatment of capsulitis of the shoulder. In: Proceedings of third international conference of surgery of the shoulder. Tokyo: Professional Postgraduate Services, 1987:204-8

18 Frozen shoulder [editorial]. N Z Med 7 1985:98:1039-40.

19 Cyriax J. Textbook of orthopaedic medicine. Vol 1. 6th ed. London: Baillière Tindall, 1975:229-43.

20 Barton MAJ, Wallace WA, Johnson F. Clinically useful measures of shoulder strength. In: Copeland $\mathrm{K}$ ed. Progress reports on electronics in medicine and biology. London: Institutition of Electronic and Radio Engineers, 1986: 185-92.

21 Robinson ND. An assessment of the benefits of local steroid injection in the treatment of painful arc syndrome of the shoulder (dissertation) Nottingham: University of Nottingham, 1987.

22 Crriax J, Russell G. Textbook of orthopaedic medicine. Vol 2. 9th ed. London: Baillière Tindall, 1977:164-6.

23 Frozen shoulder [editorial]. Lancet 1985;i:87-8.

24 Mattews JNS, Altman DG, Campbell J, Royson P. Analysis of serial measurements in medical research. BMF 1990;300:230-5.

25 Patrick $M$, Docherty $M$. Facial flushing after intra-articular injection of steroid. BMF 1987;295:1380.

26 Haines JF, Hargadon EJ. Manipulation as the primary treatment of the frozen shoulder. F R Coll Surg Edinb 1982;27 (5):271-5.

27 Bayley JIL, Kessel L. Treatment of the frozen shoulder by manipulation: a pilot study. In: Rowe CR, ed. The shoulder. New York: Churchill Livingstone, 1988: 118-23.

(Accepted 25 April 1991)

\title{
Impact of variability among surgeons on postoperative morbidity and mortality and ultimate survival
}

\author{
C S McArdle, D Hole
}

\section{Abstract}

Objective-To assess the differences among surgeons in postoperative complications, postoperative mortality, and survival in patients undergoing surgery for colorectal cancer.

Design-Prospective study of patients with colorectal cancer managed by one of 13 consultant surgeons, none of whom had a special interest in colorectal surgery.

Setting-Royal Infirmary, Glasgow.

University Department of Surgery, Royal Infirmary, Glasgow G31 2ER

C S McArdle, FRCS

consultant surgeon

Cancer Surveillance Unit, Ruchill Hospital, Glasgow G20

D Hole, MSC, senior

statistician

Correspondence to:

Mr McArdle.

BMF 1991;302:1501-5
Patients-645 sequential patients with colorectal cancer presenting over the six years from 1974 to 1979.

Main outcome measures-Postoperative complications, postoperative mortality (within $\mathbf{3 0}$ days), and survival (up to 10 years); predictive factors for postoperative mortality and survival; and relative hazard rate ratios for individual surgeons.

Results - The proportion of patients undergoing apparently curative resection varied among surgeons from $40 \%$ to $76 \%$; overall postoperative mortality varied from $8 \%$ to $30 \%$. After curative resection postoperative mortality varied from $0 \%$ to $20 \%$, local recurrence from $0 \%$ to $21 \%$, and the rate of anastomotic leak from $0 \%$ to $25 \%$. Survival at 10 years in patients who underwent curative resection varied from $20 \%$ to $63 \%$, two year survival in those who underwent palliative resection varied from $7 \%$ to $32 \%$, and median survival in those who underwent palliative diversion varied from one to eight months. The hazard rate ratios among individual surgeons, taking into account the identified risk factors, varied from 0.56 to 2.03 , from 0.17 to 1.92 , and from 0.57 to 1.50 for curative resection, palliative resection, and palliative diversion, respectively.

Conclusion-There were significant variations in patient outcome among surgeons after surgery for colorectal cancer; such differences compromise survival. A considerable improvement in overall survival might be achieved if such surgery were undertaken by surgeons with a special interest in colorectal surgery or surgical oncology.

\section{Introduction}

Previous studies have drawn attention to the extent of the intersurgeon variability in surgery for colorectal cancer. ${ }^{12}$ Differences in surgeon related variables, 
however, should not be considered in isolation. Clearly the differences in outcome may simply reflect variations in patient population: one surgeon may have a high proportion of elderly patients presenting as emergencies with advanced lesions whereas another might deal mainly with referred patients, who tend to be younger, fitter, and have less advanced tumours. Furthermore, faced with an identical problem a conservative surgeon might opt for limited surgery, thereby making a compromise between control of symptoms and ultimate survival, whereas a more aggressive surgeon might undertake a more radical procedure, thereby risking technical complications in an attempt to improve quality and duration of life.

We evaluated the relation between intersurgeon variability and outcome in patients undergoing surgery for colorectal cancer.

\section{Patients and methods}

A total of 645 patients presenting to the Royal Infirmary, Glasgow, between 1 January 1974 and 31 December 1979 with a clinical diagnosis of colorectal cancer were included in the study. ${ }^{3}$ The management of these patients was supervised by several consultant general surgeons, none of whom had a specific interest in colorectal surgery. Data on patients recorded prospectively by a single observer included age, sex, site of cancer, nature of surgery, and postoperative morbidity and mortality.

The patients were deemed to have had a curative resection if the surgeon considered that there was no macroscopic residual tumour once resection had been completed. Patients with distant metastases who underwent resection or in whom inadequate local clearance was achieved were deemed to have had a palliative resection. Patients who had palliative diversion were given a proximal defunctioning colostomy or bypass, the primary tumour being left in situ. In a few patients surgical intervention was deemed inappropriate or only laparotomy was performed.

All patients were followed up at three monthly intervals for two years at a designated colorectal cancer clinic, at six monthly intervals for a further three years, and thereafter annually up to 10 years. The dates of first detected recurrence and death were recorded.

The percentages of patients surviving after two years and 10 years were calculated by using standard life table techniques. ${ }^{+}$To compare survival in patients treated by different surgeons while taking into account patients' different presenting characteristics, a standard two step approach was used. Firstly, significant predictive factors for survival were identified by using Cox's proportional hazards model ${ }^{6}$ without reference to which surgeon had operated. Secondly, each individual surgeon was compared with all the others combined by Cox's proportional hazards model, incorporating the identified predictive factors. The model produces as the measure of output the relative hazard ratio, which indicates time specific mortality for the selected surgeon compared with that for all other surgeons combined. Values greater than one indicate a higher mortality than average. The procedure was carried out separately for patients undergoing curative resection, palliative resection, and palliative diversion and for all patients combined.

\section{Results}

The tumour was resected in $458(71 \cdot 0 \%)$ patients; of these, 338 resections were regarded as curative and 120 as palliative. Palliative diversion was performed in 132 $(20 \cdot 5 \%)$ of patients and $55(8 \cdot 5 \%)$ underwent only laparotomy or had no surgical treatment.

The number of patients dealt with by individual surgeons varied from 21 to 98 (table I). Fifty four patients were cared for by a small group of surgeons, usually with an interest in a specialty other than the abdomen, each performing only a few procedures; often the colorectal cancer was an incidental finding. Results for these patients are not reported separately but were included in the analysis for all patients.

The proportion of patients undergoing curative resection varied among surgeons from $40 \%$ to $76 \%$, the

TABLE I-Surgical procedure and postoperative mortality in patients who had surgery for colorectal cancer performed by one of 13 surgeons ( $A$-M). Figures are numbers (percentages) of patients

\begin{tabular}{|c|c|c|c|c|c|c|c|c|c|c|c|c|c|c|}
\hline & $\underset{(\mathbf{n}=98)}{\mathrm{A}}$ & $\underset{(n=66)}{B}$ & $\begin{array}{c}\mathrm{C} \\
(\mathbf{n}=58)\end{array}$ & $\begin{array}{c}\mathrm{D} \\
(\mathbf{n}=52)\end{array}$ & $\underset{(n=52)}{E}$ & $\begin{array}{c}F \\
(n=46)\end{array}$ & $\begin{array}{c}\mathbf{G} \\
(\mathbf{n}=38)\end{array}$ & $\begin{array}{c}\mathbf{H} \\
(\mathbf{n}=37)\end{array}$ & $\begin{array}{c}\mathrm{I} \\
(\mathrm{n}=36)\end{array}$ & $\begin{array}{c}\mathbf{J} \\
(\mathbf{n}=34)\end{array}$ & $\begin{array}{c}\mathbf{K} \\
(\mathbf{n}=32)\end{array}$ & $\begin{array}{c}\mathbf{L} \\
(\mathbf{n}=21)\end{array}$ & $\underset{(\mathbf{n}=21)}{M}$ & $\begin{array}{c}\text { All } \\
\text { patients } \\
(\mathrm{n}=645)\end{array}$ \\
\hline Curative resection & $47(48)$ & $34(52)$ & $31(53)$ & $34(65)$ & $21(40)$ & $30(65)$ & $22(58)$ & $15(41)$ & $19(53)$ & $14(41)$ & $16(50)$ & $12(57)$ & $16(76)$ & $338(52)$ \\
\hline Palliative resection & $13(13)$ & $14(21)$ & $14(24)$ & $8(15)$ & $9(17)$ & $2(4)$ & $9(24)$ & $10(27)$ & $10(28)$ & $10(29)$ & $7(22)$ & $6(29)$ & $1(5)$ & $120(19)$ \\
\hline Palliative diversion & $31(32)$ & $10(15)$ & $8(14)$ & $9(17)$ & $15(29)$ & $13(28)$ & $5(13)$ & $8(22)$ & $5(14)$ & $5(15)$ & $7(22)$ & $3(14)$ & $3(14)$ & $132(20)$ \\
\hline $\begin{array}{l}\text { Operation performed by surgeon in } \\
\text { training }\end{array}$ & $25(26)$ & $2(3)$ & $27(47)$ & $16(31)$ & $9(17)$ & $13(28)$ & $6(16)$ & $5(14)$ & $24(67)$ & $9(26)$ & $5(16)$ & $12(57)$ & $10(48)$ & $183(28)$ \\
\hline Postoperative mortality & $16(16)$ & $8(12)$ & $9(16)$ & $7(13)$ & $15(29)$ & $5(11)$ & $3(8)$ & $11(30)$ & $5(14)$ & $7(21)$ & $4(13)$ & $2(10)$ & $3(14)$ & $105(16)$ \\
\hline
\end{tabular}

*Includes 21 patients who underwent laparotomy alone and 34 who had no surgical procedure.

TABLE II - Rate of complications after surgery for colorectal cancer performed by one of 13 surgeons (A-M). Figures are numbers (percentages) of patients

\begin{tabular}{|c|c|c|c|c|c|c|c|c|c|c|c|c|c|c|}
\hline Complication & A & B & $\mathrm{C}$ & $\mathrm{D}$ & $\mathrm{E}$ & $\mathrm{F}$ & G & $\mathrm{H}$ & I & $\mathbf{J}$ & $\mathrm{K}$ & $\mathrm{L}$ & $M$ & $\underset{\text { patients }}{\text { All }}$ \\
\hline Wound infection & $22(22)$ & $19(29)$ & $15(28)$ & $11(19)$ & $3(6)$ & $7(15)$ & $10(26)$ & $9(24)$ & $8(22)$ & $10(35)$ & $8(25)$ & $3(14)$ & $5(24)$ & $136(22)$ \\
\hline Wound dehiscence & $7(7)$ & $4(6)$ & $4(7)$ & $1(2)$ & $1(2)$ & $2(4)$ & $2(5)$ & $4(11)$ & $1(3)$ & & $2(6)$ & $1(5)$ & $2(10)$ & $31(5)$ \\
\hline Chest infection & $12(12)$ & $10(15)$ & $11(20)$ & $8(14)$ & $3(6)$ & $5(11)$ & $6(16)$ & $9(24)$ & $7(19)$ & $5(17)$ & $4(13)$ & $2(10)$ & $3(14)$ & $88(14)$ \\
\hline Intraperitoneal abscess & $3(3)$ & $2(3)$ & $1(2)$ & $3(5)$ & & $2(4)$ & $2(5)$ & $2(5)$ & $1(3)$ & & $2(6)$ & $2(10)$ & $2(10)$ & $23(4)$ \\
\hline Anastomotic leak/fistula & $7(7)$ & $5(8)$ & $5(9)$ & $1(2)$ & $1(2)$ & l(2) & $5(13)$ & $3(8)$ & $4(11)$ & $5(17)$ & $7(22)$ & $2(10)$ & $3(14)$ & $50(8)$ \\
\hline
\end{tabular}

${ }^{\star}$ Excludes 34 patients who had no surgical procedure.

TABLE III - Rate of complication and postoperative mortality after curative resection performed by one of 13 surgeons (A-M). Figures are numbers (percentages) of patients

\begin{tabular}{|c|c|c|c|c|c|c|c|c|c|c|c|c|c|c|}
\hline & $\begin{array}{c}\mathrm{A} \\
(\mathrm{n}=47)\end{array}$ & $\underset{(n=34)}{B}$ & $\begin{array}{c}C \\
(n=31)\end{array}$ & $\underset{(n=34)}{\mathrm{D}}$ & $\underset{(n=21)}{E}$ & $\underset{(\mathbf{n}=30)}{\mathbf{F}}$ & $\begin{array}{c}\mathrm{G} \\
(\mathrm{n}=22)\end{array}$ & $\underset{(\mathbf{n}=15)}{\mathbf{H}}$ & $\underset{(n=19)}{I}$ & $\underset{(n=14)}{J}$ & $\underset{(n=16)}{K}$ & $\underset{(\mathrm{n}=12)}{\mathrm{L}}$ & $\underset{(n=16)}{M}$ & $\begin{array}{c}\text { All } \\
\text { patients } \\
(\mathbf{n}=338)\end{array}$ \\
\hline Wound dehiscence & $4(9)$ & $1(3)$ & $3(10)$ & $1(3)$ & $1(5)$ & $1(3)$ & $2(9)$ & $3(20)$ & & & $1(6)$ & $1(8)$ & $2(13)$ & $20(6)$ \\
\hline Intraperitoneal sepsis & $2(4)$ & & & $2(6)$ & & $2(7)$ & & $1(7)$ & & & $1(6)$ & $2(17)$ & $2(13)$ & $12(4)$ \\
\hline Anastomotic leak/fistula & $5(11)$ & $3(9)$ & $1(3)$ & $1(3)$ & & $1(3)$ & $2(9)$ & $3(20)$ & $3(16)$ & $1(7)$ & $4(25)$ & $2(17)$ & $2(13)$ & $29(9)$ \\
\hline Local recurrence & $6(13)$ & $4(12)$ & $2(6)$ & $7(21)$ & $1(5)$ & $1(3)$ & $3(14)$ & $3(20)$ & $1(5)$ & $2(14)$ & $1(6)$ & $1(8)$ & & $37(11)$ \\
\hline Postoperative mortality & $3(6)$ & $1(3)$ & $1(3)$ & $4(12)$ & $3(14)$ & $2(7)$ & & $3(20)$ & $2(11)$ & $1(7)$ & & & $1(6)$ & $21(6)$ \\
\hline
\end{tabular}




\begin{tabular}{|c|c|c|c|c|c|c|c|c|c|c|c|c|c|c|}
\hline & A & B & $\mathrm{C}$ & $\mathrm{D}$ & $\mathrm{E}$ & $\mathrm{F}$ & $\mathrm{G}$ & $\mathrm{H}$ & I & $\mathrm{J}$ & $\mathrm{K}$ & $\mathrm{L}$ & M & $\begin{array}{c}\text { All } \\
\text { patients }\end{array}$ \\
\hline \multicolumn{15}{|l|}{ Palliative resection: } \\
\hline No of patients & 13 & 14 & 14 & 8 & 9 & 2 & 9 & 10 & 10 & 10 & 7 & 6 & 1 & 120 \\
\hline Anastomic leak/fistula & & $2(14)$ & $4(29)$ & & $1(11)$ & & & & $1(10)$ & $3(30)$ & $3(43)$ & & & $14(12)$ \\
\hline Postoperative mortality & $3(23)$ & $1(7)$ & $4(29)$ & $1(13)$ & $1(11)$ & & $1(11)$ & $3(30)$ & & $2(20)$ & & $1(17)$ & & $17(14)$ \\
\hline \multicolumn{15}{|l|}{ Palliative diversion: } \\
\hline No of patients & 31 & 10 & 8 & 9 & 15 & 13 & 5 & 8 & 5 & 5 & 7 & 3 & 3 & 132 \\
\hline Postoperative mortality & $7(23)$ & $1(10)$ & $2(25)$ & $2(22)$ & $6(40)$ & $2(15)$ & & 338 & $2(40)$ & $120)$ & $3(43)$ & 133 & $1(33)$ & $32(24)$ \\
\hline
\end{tabular}

TABLE V-Percentage survival after curative and palliative resection and palliative diversion performed by one of 13 surgeons $(A-M)$

\begin{tabular}{|c|c|c|c|c|c|c|c|c|c|c|c|c|c|c|}
\hline & A & $\mathrm{B}$ & $\mathrm{C}$ & $\mathrm{D}$ & $\mathrm{E}$ & $\mathrm{F}$ & G & $\mathrm{H}$ & I & $\mathrm{J}$ & $\mathrm{K}$ & $\mathrm{L}$ & $M$ & $\begin{array}{c}\text { All } \\
\text { patients }\end{array}$ \\
\hline \multicolumn{15}{|l|}{ Curative resection: } \\
\hline No of patients & 47 & 34 & 31 & 34 & 21 & 30 & 22 & 15 & 19 & 14 & 16 & 12 & 16 & 338 \\
\hline Survival after 10 years $(\%)$ & 44 & 31 & 57 & 24 & 37 & 32 & 50 & 20 & 40 & 63 & 61 & 32 & 42 & 41 \\
\hline \multicolumn{15}{|l|}{$\begin{array}{l}\text { Palliative resection: } \\
\text { Pat }\end{array}$} \\
\hline No of patients & 13 & 14 & 14 & 8 & 9 & 2 & 9 & 10 & 10 & 10 & 7 & 6 & 1 & 120 \\
\hline Survival after 2 years (\%) & 10 & 21 & 7 & 32 & 13 & 100 & 22 & 20 & 10 & 10 & 18 & 17 & 100 & 18 \\
\hline \multicolumn{15}{|l|}{$\begin{array}{l}\text { Palliative diversion: } \\
\text { Pivis }\end{array}$} \\
\hline No of patients & 31 & 10 & 8 & 9 & 15 & 13 & 5 & 8 & 5 & 5 & 7 & 3 & 3 & 132 \\
\hline Median survival (months) & 6 & 4 & 2 & 2 & 1 & 8 & 4 & 3 & 2 & 2 & 2 & 8 & 5 & 3 \\
\hline
\end{tabular}

proportion undergoing palliative resection from $4 \%$ to $29 \%$, and the proportion undergoing palliative diversion from $13 \%$ to $32 \%$. Overall postoperative mortality varied among surgeons from $8 \%$ to $30 \%$. The proportion of procedures undertaken by surgeons in training varied from $3 \%$ to $67 \%$.

Table II gives the overall rates of complications. The incidence of wound sepsis varied among surgeons from $6 \%$ to $35 \%$ and the incidence of wound dehiscence from $0 \%$ to $11 \%$. The incidence of chest infection, as defined by clinical criteria, varied from $6 \%$ to $24 \%$, that of subphrenic or pelvic abscess from $0 \%$ to $10 \%$, and that of clinically apparent anastomotic leak or fistula from $2 \%$ to $22 \%$.

Table III gives the incidence of complications after curative resection. Postoperative mortality varied among surgeons from $0 \%$ to $20 \%$. The incidence of local recurrence varied from $0 \%$ to $21 \%$, of intraperitoneal sepsis from $0 \%$ to $17 \%$, and of overt anastomotic leakage or fistula from $0 \%$ to $25 \%$. Table IV gives the incidence of complications and postoperative mortality after palliative resection or diversion.

Table $\mathrm{V}$ gives the survival rates after curative

TABLE VI-Relative hazard ratios for factors associated with survival after three types of surgery for colorectal cancer

\begin{tabular}{lccc}
\hline Prognostic factor & $\begin{array}{c}\text { Curative } \\
\text { resection }\end{array}$ & $\begin{array}{c}\text { Palliative } \\
\text { resection }\end{array}$ & $\begin{array}{c}\text { Palliative } \\
\text { diversion }\end{array}$ \\
\hline Dukes's C stage & $1 \cdot 51^{\star \star}$ & & \\
Emergency admission & $1 \cdot 46^{\star}$ & & $1 \cdot 66^{\star}$ \\
Local spread of cancer & $1 \cdot 46^{\star}$ & & \\
Poor differentiation of tumour & $1 \cdot 59^{\star}$ & & \\
Age $\geqslant 65$ years & $1 \cdot 85^{\star \star}$ & & \\
Male & $1 \cdot 37^{\star}$ & $1.62^{\star}$ & \\
Distant metastases & & & \\
\hline${ }^{\star} \mathrm{p}<0 \cdot 05 ; \star \star \mathrm{p}<0 \cdot 01$. & &
\end{tabular}

resection, palliative resection, and palliative diversion. Disease related survival at 10 years after "curative" resection varied from $20 \%$ to $63 \%$. Survival at two years after palliative resection varied from $7 \%$ to $32 \%$ (excluding surgeons $\mathrm{F}$ and $\mathrm{M}$ who treated only two cases and one case, respectively), and median survival after palliative diversion varied from one to eight months.

On the basis of multivariate analysis we identified the following factors associated with postoperative mortality: age, emergency admission, and pre-existing cardiac or respiratory disease. Similarly, the presence or absence of local spread of the tumour, Dukes's stage, degree of differentiation of tumour, age, emergency admission, and sex influenced survival after curative resection (table VI). Predictive factors after palliative resection and palliative diversion were the presence of metastatic spread at laparotomy and emergency surgery, respectively.

Table VII gives the hazard rate ratios for each surgeon adjusted for the above factors, for curative resection, palliative resection, and palliative diversion. The adjusted ratio for patients undergoing curative resection varied from 0.56 to 2.03 . The corresponding adjusted ratios for palliative resection and palliative diversion varied from 0.17 to 1.92 and from 0.57 to $1 \cdot 50$, respectively.

Table VIII shows unadjusted and adjusted hazard rate ratios for two individual surgeons ( $\mathbf{I}$ and $\mathrm{J}$ ). Surgeon I had a higher than average number of patients presenting as emergencies or with local spread of tumour; the relative hazard ratio therefore improved from 0.92 to 0.69 after adjustment. In contrast, surgeon $\mathrm{J}$ had a lower than average number of patients with local spread of tumour; the relative hazard ratio therefore worsened after adjustment.

TABLE VII-Unadjusted hazard ratios and hazard ratios adjusted for associated prognostic factors for patients operated on for colorectal cancer by one of 13 surgeons (A-M)

\begin{tabular}{|c|c|c|c|c|c|c|c|c|c|c|c|c|c|}
\hline & A & B & $\mathrm{C}$ & $\mathrm{D}$ & $\mathrm{E}$ & $\mathrm{F}$ & G & $\mathrm{H}$ & I & $\mathrm{J}$ & $\mathrm{K}$ & L & M \\
\hline \multicolumn{14}{|c|}{ Curative resection: } \\
\hline Unadjusted & $0 \cdot 96$ & $1 \cdot 30$ & 0.58 & 1.74 & $1 \cdot 15$ & 1.09 & 0.83 & 1.91 & 0.92 & 0.57 & $0 \cdot 62$ & $1 \cdot 09$ & 0.98 \\
\hline Adjusted & $1 \cdot 15$ & $1 \cdot 28$ & $0 \cdot 56^{\star}$ & $1.85 t$ & 1.07 & $1 \cdot 11$ & 0.86 & $2 \cdot 03 \ddagger$ & 0.69 & $0 \cdot 80$ & 0.63 & 0.94 & 0.84 \\
\hline \multicolumn{14}{|c|}{ Palliative resection: } \\
\hline Unadjusted & $1 \cdot 26$ & 0.94 & 1.53 & 0.62 & $0 \cdot 90$ & $0 \cdot 16$ & 0.89 & 1.24 & $1 \cdot 11$ & 1.48 & 0.69 & 1.68 & 0.56 \\
\hline Adjusted & 1.76 & 0.80 & 1.33 & 0.64 & 0.84 & $0 \cdot 17$ & 0.94 & 1.49 & $1 \cdot 15$ & $1 \cdot 34$ & 0.67 & 1.92 & $0 \cdot 41$ \\
\hline \multicolumn{14}{|c|}{ Palliative diversion: } \\
\hline Unadjusted & 0.65 & 0.87 & $1 \cdot 51$ & $1 \cdot 38$ & $1 \cdot 41$ & 0.61 & 0.77 & 1.67 & 1.69 & $1 \cdot 34$ & 0.97 & 0.97 & $0 \cdot 90$ \\
\hline Adjusted & 0.75 & $0 \cdot 87$ & $0 \cdot 83$ & $1 \cdot 37$ & $1 \cdot 50$ & 0.57 & 0.76 & 1.28 & $1 \cdot 41$ & 0.99 & 0.87 & $1 \cdot 13$ & 0.86 \\
\hline \multicolumn{14}{|l|}{ All patients: } \\
\hline Unadjusted & 1.07 & 1.09 & $0 \cdot 78$ & $1 \cdot 11$ & 1.29 & 0.78 & 0.87 & 1.69 & 0.99 & 0.98 & 0.80 & 1.05 & $0 \cdot 64$ \\
\hline Adjusted & $1 \cdot 10$ & 1.03 & 0.87 & 1.09 & 1.09 & $0 \cdot 86$ & $0 \cdot 86$ & 1.619 & 0.91 & $1 \cdot 05$ & 0.59 & 0.97 & 0.79 \\
\hline
\end{tabular}




\begin{tabular}{|c|c|c|c|c|c|c|c|c|}
\hline \multirow[b]{2}{*}{ Surgeon } & \multirow{2}{*}{$\begin{array}{l}\text { Dukes's } \\
\text { stage C }\end{array}$} & \multirow{2}{*}{$\begin{array}{l}\text { Local } \\
\text { spread of } \\
\text { tumour }\end{array}$} & \multirow{2}{*}{$\begin{array}{l}\text { Emergency } \\
\text { admissions }\end{array}$} & \multirow{2}{*}{$\begin{array}{c}\text { Poorly } \\
\text { differentiated } \\
\text { tumour }\end{array}$} & \multirow[b]{2}{*}{ Age $\geqslant 65$} & \multirow[b]{2}{*}{ Male } & \multicolumn{2}{|c|}{ Relative hazard ratio } \\
\hline & & & & & & & Unadjusted & Adjusted \\
\hline I & $8(42)$ & $7(37)$ & $9(47)$ & $2(11)$ & $4(21)$ & $9(47)$ & 0.92 & $0 \cdot 69$ \\
\hline J & $7(50)$ & & $5(36)$ & $1(7)$ & $3(21)$ & $7(50)$ & 0.57 & 0.80 \\
\hline All & $142(42)$ & $56(17)$ & $93(28)$ & $57 .(17)$ & $66(20)$ & $166(49)$ & & \\
\hline
\end{tabular}

\section{Discussion}

Most surgeons are aware that the incidence of technical complications varies widely among individual surgeons. Fielding et al drew attention to the differences in rates of clinically evident anastomotic leakage after resection for large bowel cancer. ${ }^{1}$ The overall incidence of anastomotic leakage was $13 \%$, but the incidence varied among surgeons from less than $5 \%$ to over $30 \%$. This disparity did not seem to be due to differences in the proportions of technically demanding procedures-for example, anterior resection or palliative resection-undertaken by individual surgeons. In the same study anastomotic leakage was associated with a twofold increase in hospital stay and a threefold increase in mortality during hospital stay.

The same researchers subsequently highlighted the varying incidence of local recurrence after apparently curative resection. ${ }^{2}$ Factors associated with local recurrence included Dukes's classification; the presence of obstruction or perforation; tumour mobility; and, for rectal tumours, the type of surgery performed. The rate of local recurrence differed among surgeons from less than $5 \%$ to over $20 \%$. The differences persisted after correction for the associated factors.

The results of our study are similar. To some extent, however, the variations in outcome simply reflected differences in patient population. For example, surgeons undertaking fewer procedures tended to deal with a higher proportion of emergency admissions in more elderly patients with more advanced lesions, whereas surgeons dealing with larger numbers of patients often had a higher proportion of younger, fitter patients presenting with smaller lesions on an elective basis. Nevertheless, even after adjusting for known risk factors substantial differences remained.

It did not seem that the differences were due to some surgeons undertaking more radical surgery, thereby risking complications, in an attempt to improve quality of life and duration of survival. In this study the surgeon with the highest rate of curative resection had an incidence of local recurrence of zero. In contrast the surgeon with the second lowest rate of curative resection had the second highest rate of local recurrence, highest rate of wound dehiscence, and one of the highest rates of anastomotic leak. There is therefore little evidence to suggest that the more conservative surgeon has a lower rate of complications; indeed the reverse may be true.

\section{VARIABILITY IN SURGICAL TECHNIQUE}

Clearly the differences in the incidence of technical complications is disturbing. A wound dehiscence rate of $20 \%$ after curative resection is unacceptable. The criteria for adequate wound closure have been clearly established, and in many large studies the wound dehiscence rate after elective abdominal surgery is less than $2 \%$.

The factors contributing to anastomotic breakdown are well recognised. Clearly surgical technique is a critical factor; so too is good postoperative care. Several studies have emphasised the importance of adequate tissue perfusion and oxygen delivery to the anastomosis. There is a critical oxygen level below which anastomotic leakage is inevitable. ${ }^{8}$ Intraoperative fluid losses are often larger than realised; as a result postoperative splanchnic perfusion is less than optimal. This may be compounded by significant hypoxaemia due to atelectasis or chest infection, to which these often elderly, frail patients are prone.

It is also clear that local recurrence represents a failure of surgical technique. It is usually relatively easy to obtain adequate clearance of intraperitoneal tumours but adequate resection of rectal and rectosigmoid tumours remains problematical. Quirke et al have shown that local recurrence after apparently curative resection is due to the presence of lateral tumour spread. ${ }^{9}$ More meticulous and careful dissection of the pararectal tissues may therefore reduce the incidence of local recurrence.

\section{VARIABILITY IN ASSESSMENT}

Furthermore, our results show substantial differences in overall survival. In part these variations may have been due to differences in the individual surgeon's assessment as to whether or not "cure" was achieved. In patients in whom the adequacy of resection was borderline an optimistic surgeon might believe he or she has achieved cure, whereas a more pessimistic surgeon might be concerned that he or she had merely achieved palliation. If the surgeon is too optimistic survival after curative resection may be less than expected; in contrast, if the surgeon is unduly pessimistic survival after what was regarded as a palliative resection may be better than expected.

\section{VARIABILITY AMONG SURGEONS}

These interpretative differences, however, are not the major reason for the variations in outcome. Although in this study the proportion of patients undergoing curative resection, palliative resection, and palliative bypass varied widely, it is interesting to note that, for individual surgeons, survival after both curative and palliative resection tended to be either better or worse than average. These differences persisted even after correction for the known risk factors.

In this study, therefore, there were wide variations among surgeons in the rates of resection, postoperative mortality, and overall survival. Furthermore, it seems clear that the choice of surgery might have been in some cases suboptimal. For example, there is some evidence that resection was not attempted in the presence of tumour adherence, particularly in the rectum and rectosigmoid junction, and in elderly people. Previous studies have shown that in a significant proportion of these patients the adherence is due to inflammatory reaction rather than tumour infiltration and that many of these lesions can be successfully excised.

Furthermore, the variation in the proportion of procedures undertaken by surgeons in training is worrying. The confidential enquiry into perioperative deaths has clearly drawn attention to the dangers of leaving high risk procedures to junior surgeons without adequate supervision. ${ }^{10}$

\section{CONCLUSIONS}

The conclusions are clear. Some surgeons perform less than optimal surgery; some are less competent 
technically than their colleagues; and some fail to supervise surgeons in training adequately. These factors may compromise survival. The results support the contention that surgery for colorectal cancer should be undertaken by surgeons with a special interest in colorectal surgery or surgical oncology; this observation has important implications for surgical training.

At present considerable effort and resources are being poured into large multicentre studies of adjuvant chemotherapy and radiotherapy in an effort to provide marginal improvement in survival of patients with colorectal cancer. If by more meticulous attention to detail the results of surgery could be improved, and our results suggest that this would not be difficult, the impact on survival might be greater than that of any of the adjuvant therapies currently under study.

This study was made possible by the foresight of Professor $\mathrm{L} \mathrm{H}$ Blumgart and $\mathrm{Mr} \mathrm{C}$ B Wood, who established the colorectal cancer follow up clinic in 1974. The original data collection was funded by Cancer Research Campaign.
1 Fielding LP, Stewart-Brown S, Blesovsky L, Kearney G. Anastomotic integrity after operations for large-bowel cancer: a multicentre study. $B M J$ 1980;281:411-4

2 Phillips RKS, Hittinger R, Blesovsky L, Fry JS, Fielding LP. Local recurrence following "curative" surgery for large bowel cancer: I. The recurrence following "curative" surg

3 McArdle CS, Hole D, Hansell D, Blumgart LH, Wood CB. Prospective study of colorectal cancer in the west of Scotland: ten-year follow-up. Br f Surg of colorectal cance

4 Kaplan EL, Meier P. Nonparametric estimation from incomplete observations. fournal of the American Statistical Association 1958;53:457-81.

5 Breslow NE, Day NE. Statistical methods in cancer research. Vol II - The design and analysis of cohort studies. Lyons: International Agency for Research in Cancer, 1987. Scientific publication No 82.

6 Cox DR. Regression models and life tables. Journal of the Royal Statistical Society $(B)$ 1972;34:187-220.

7 Ausobsky JR, Evans M, Pollock AV. Does mass closure of midline laparotomies stand the test of time? A random control clinical trial. Ann R Coll Surg Engl 1985;67:159-62.

8 Shandall A, Lowndes R, Young HL. Colonic anastomic healing and oxygen tension. Br f Surg 1985;72:606-9.

9 Quirke P, Purdy P, Dickson MS, Williams NS. Local recurrence of rectal adenocarcinoma due to inadequate surgical resection. Histopathological study of lateral tumour spread and surgical excision. Lancet 1986;ii:996-8.

10 Buck N, Devlin HB, Lunn JN. The report of the confidential enquiry into perioperative deaths. London: Nuffield Provincial Hospital Trust/King's Fund, 1987

(Accepted 25 April 1991)

\section{Golf related head injuries in children}

\section{R A Smith, S Ling, F W Alexander}

Department of Paediatrics,

Newcastle General

Hospital, Newcastle upon

Tyne NE4 6BE

R A Smith, MRCP, senior registrar

$\mathrm{S}$ Ling, $\mathrm{MB}$, senior house

officer

F W Alexander, FRCP,

consultant

Correspondence to:

Dr Alexander.

BMF 1991;302:1505-6 year.

\section{Patients, methods, and results}

Golf is the commonest cause of serious sports related head injuries in children, despite it being a predominantly adult game. ' Little attention, however, has been given to how the injuries actually occur. We report a series of children with head injuries due to golf who presented to a regional neurosurgical centre over one

We studied the case notes of all children admitted to our hospital over one year with head injuries. The hospital is a regional referral centre for children with head injuries. Jennett and Murray's definition of head injury was used. ${ }^{2}$ Where the details of the cause of injury were incomplete further information was obtained by contacting the parents.

In all, the case notes of 232 children were studied ( 139 boys and 93 girls; mean (SD) age $6 \cdot 7$ (4.33) years). Forty one children were referred from outside Newcastle.

The causes of the head injuries fell into four main categories: 113 were due to falls; 84 to road traffic accidents; 27 to sports injuries, including leisure related activities; and eight to non-accidental injury.

Of the 27 cases of sports related head injuries, 11 were associated with golf; five with skateboards; five with football; three with horse riding; and one each with swimming, ice skating, and kite flying. The 11 children with golf associated injuries were all boys (mean age $9 \cdot 89(2 \cdot 84)$ years). Of these, nine had skull fractures; the table gives details of the head injuries. Seven patients required elevation of the depressed skull fracture under general anaesthesia. None required admission to the intensive care unit. All were clinically well on discharge from hospital. The mean (range) duration of inpatient stay was $5 \cdot 18$ (1-8) days.

Nine of the children were injured when standing behind another child swinging a club; the head was struck on either the backswing or the follow through. Two children were hit on the head by golf balls struck by other children. In seven of the accidents the children had borrowed a golf club and were playing in either parkland or local fields. In one case the child had found the club in a field. Only one of the accidents occurred on a golf course; another occurred at the practice range of a course, and a third on a crazy golf course. On no occasion was play supervised by an adult.

Details of golf related head injuries in 11 boys

\begin{tabular}{|c|c|c|}
\hline Case No & $\begin{array}{c}\text { Age } \\
\text { (years) }\end{array}$ & Injury \\
\hline 1 & 8 & Depressed compound left frontal skull fracture \\
\hline 2 & 10 & Depressed compound right parietal skull fracture \\
\hline 3 & 6 & Depressed compound left orbital ridge skull fracture \\
\hline 4 & 10 & $\begin{array}{l}\text { Depressed compound left temporal skull fracture. } \\
\text { Extradural haematoma requiring left frontal } \\
\text { craniotomy and evacuation }\end{array}$ \\
\hline 5 & 13 & Depressed compound left supraorbital skull fracture \\
\hline 6 & 12 & Depressed compound right parietal skull fracture \\
\hline 7 & 14 & $\begin{array}{l}\text { Depressed compound right parietal skull fracture. } \\
\text { Cerebral contusion on computed tomography }\end{array}$ \\
\hline 8 & 10 & Deep laceration to forehead \\
\hline 9 & 6 & Depressed compound left parietal skull fracture \\
\hline 10 & 6 & Cephalhaematoma (left frontoparietal region) \\
\hline 11 & 14 & Depressed compound right frontoparietal skull fracture \\
\hline
\end{tabular}

\section{Comment}

In our series $40 \%$ of the sports related head injuries, $50 \%$ of all the depressed skull fractures, $18 \%$ of all skul fractures, and $4 \cdot 7 \%$ of admissions were associated with golf. Strang et al found that the proportion of head injuries that were sports related in all patients attending Scottish accident departments was $12 \%$, and for children under 15 years $21 \% .^{3}$ These injuries accounted for $14 \%$ of admissions to general surgical wards and $7 \%$ of admissions to a regional Scottish neurosurgical unit. ${ }^{2}$ Neither of these studies gave a breakdown of the sports concerned.

In a study that did not include children at play only $2.7 \%$ of 1900 admissions to a regional head injury unit were due to sports injuries. ${ }^{1}$ Golf was the commonest associated sport, causing $27 \%$ of all sports injuries. All were in boys under 16 (mean age 10). In a study of 400 patients with depressed skull fractures, sporting injuries accounted for $9 \%$, with golf by far the commonest associated sport. The fact that the other studies included adults probably explains the differences compared with our study in the incidence of golf related injuries.

While golf is a predominantly adult game, the mean age of the subjects with head injuries was about 10 years in both our study and in that of Lindsay et al.' Most of our patients were playing around with golf 